\title{
Determinants of workplace violence against clinical physicians in hospitals
}

\author{
Jeng-Cheng Wu ${ }^{1,2}$, Tao-Hsin TunG ${ }^{3,4}$, Peter Y. CheN ${ }^{5}$, Ying-Lin CheN ${ }^{3}$, \\ Yu-Wen LIN ${ }^{3}$ and Fu-Li CHEN ${ }^{3}$
}

${ }^{1}$ Department of Urology, Taipei Medical University Hospital, Taiwan, ${ }^{2}$ Department of Occupational Medicine, Taipei Medical University Hospital, Taiwan, ${ }^{3}$ Department of Public Health, College of Medicine, Fu Jen Catholic University, Taiwan, ${ }^{4}$ Department of Medical Research and Education, Cheng Hsin General Hospital, Taiwan and ${ }^{5}$ Department of Psychology, Auburn University, USA

\begin{abstract}
Determinants of workplace violence against clinical physicians in hospitals: Jeng-Cheng Wu, et al. Department of Urology, Taipei Medical University Hospital, Taiwan-Objectives: Workplace violence in the health sector is a worldwide concern. Physicians play an essential role in health-care teamwork; thus, understanding how organizational factors influence workplace violence against physicians is critical. Methods: A total of 189 physicians from three public hospitals and one private hospital in Northern Taiwan completed a survey, and the response rate was $47.1 \%$. This study was approved by the institutional review board of each participating hospital. The 189 physicians were selected from the Taipei area, Taiwan. Results: The results showed that $41.5 \%$ of the respondents had received at least one workplace-related physical or verbal violent threat, and that $9.8 \%$ of the respondents had experienced at least one episode of sexual harassment in the 3 months before the survey. Logistic regression analysis revealed that physicians in psychiatry or emergency medicine departments received more violent threats and sexual harassment than physicians in other departments. Furthermore, physicians with a lower workplace safety climate (OR=0.89; 95\% Cl=0.81-0.98) and more job demands $(\mathrm{OR}=1.15 ; 95 \% \mathrm{Cl}=1.02-1.30)$ were more likely to receive violent threats. Conclusions: This study found that workplace violence was associated with job demands and the workplace safety climate. Therefore, determining how to develop a workplace safety climate and ensure a safe job environment for physicians is a crucial management policy issue for health-care systems.
\end{abstract}

(J Occup Health 2015; 57: 540-547)

Received Apr 19, 2015; Accepted Aug 8, 2015

Published online in J-STAGE Sept 29, 2015

Correspondence to: F.-L. Chen, Department of Public Health, Fu-Jen Catholic University, No. 510, Zhongzheng Rd., Xinzhuang, New Taipei City, Taiwan (e-mail:026644@mail.fju.edu.tw)
Key words: Job demand, Physicians, Safety climate, Workplace violence

Workplace violence (WPV), defined as any intended or actual use of power (either physical or psychological) to injure, threaten, or assault a person in workrelated circumstances, in the health-care sector is a worldwide concern ${ }^{1,2)}$. Such WPV, which might be perpetrated in the form of physical violence, psychological violence, or harassment, has become a major problem affecting the health and productivity of health-care workers.

According to the limited research on the topic, more than two-thirds of physicians have experienced WPV in the workplace ${ }^{3,4)}$, and more than $50 \%$ of physicians have experienced WPV in the previous year ${ }^{5-7)}$. The reported incidences of different forms of WPV have varied; verbal threat was the most common form of WPV, with an annual incidence of $56-75 \%{ }^{5-7)}$, which was 3-6-fold higher than the annual incidence of physical violence ${ }^{5-7)}$. The incidence of WPV against physicians was also reported to vary among departments and was substantially higher in emergency medicine and psychiatry departments ${ }^{8,9)}$, which more often treat potential perpetrators such as patients with substance abuse problems or mental illness. Hospital WPV not only threatens the physical and psychological well-being of physicians but also affects their daily practice and quality of patient care and reduces the efficiency of the entire health-care system $^{1-3)}$.

The etiology of WPV is complex, and such violence cannot be prevented effectively through preventive equipment alone. Several recent studies have identified physicians' characteristics that were associated with the experience of WPV. These characteristics include, but are not limited to, age ${ }^{8)}$, gender ${ }^{4,8)}$, expe- 
rience and tenure at a hospital ${ }^{7,10,11)}$. However, a limitation of the research on organizational factors of violence in physicians is that most of the previous studies have focused on nurses and not on physicians. Indeed, organizational factors, such as patient contact volume $^{12)}$, WPV-related training intervention ${ }^{13,14)}$, social support ${ }^{12,14)}$ and safe working environment ${ }^{15,17)}$ have been demonstrated to be associated with WPV against nurses. Trenoweth (2003) found that the development of a nurse-patient positive relationships and working in a supportive team were perceived as protective factors against risk of $\mathrm{WPV}^{14)}$. Findorff, McGovern, Wall, Gerberich and Alexander (2004) also reported that moderate to high patient contact by nurses increased the odds of physical violence but that supervisor support reduced the odds of both physical and nonphysical violence ${ }^{12)}$. In addition, workplaces that actively work to cultivate a safe working environment reduced the incidence of physical violence against nurses ${ }^{17)}$. The results of a national survey of violence in emergency medicine in the U.S. indicated that most of emergency medicine physicians suffered WPV but that hospital settings only provided a smaller number of violence preventive workshops or provided self-defense training ${ }^{5)}$.

Physicians face numerous competing priorities such as caring for numerous patients vs. increasing safety regulation. How safety is emphasized relative to other competing priorities form the norms of hospitals, which inevitably affects how physicians' perceptions and expectation of whether safety concerns such as WPV are valued ${ }^{18,19)}$. According to the literature, we expect that inadequate work conditions among physicians may lead to WPV. This main aim of this study was to examine the organizational determinants of WPV for clinical physicians. The results could facilitate the development of policies and strategies to prevent and manage WPV against physicians.

\section{Methods}

\section{Subjects and procedures}

This cross-sectional study surveyed 401 physicians from 4 regional teaching hospitals (3 public and one private) in Northern Taiwan between April 2009 and June 2009. These hospitals were selected according to the convenience sampling method, and 2 of them were located in Taipei City; and the other 2 were located in New Taipei City. Between 76 and 113 physicians were recruited from each hospital. A anonymous self-administered questionnaire and written informed consent form were distributed to each recruited physician. The overall response rate was $47.1 \%$ (189 of 401 physicians).

\section{Measures}

The questionnaire contained items relating to WPV and covariate variables (i.e., personal characteristics, job demands, safety climate, organizational support, and attendance at workplace violence training courses), which are described below.

\section{Workplace violence}

Two items concerned WPV, namely whether physicians had experienced "verbal or physical violent threats" or "sexual harassment" during their routine work in the past 3 months. The respondents answered each question using a binary scale $(0=$ did not experience, 1=experienced).

\section{Independent variables}

\section{Personal characteristics}

Personal characteristics included information about respondents' gender, age, affiliated department, and tenure in his/her current department. Based on findings from some previous studies ${ }^{5,89}$, the variable of affiliated department was divided into department with high exposure to WPV (i.e., psychiatry or emergency medicine) and department with low exposure to WPV (i.e., departments other than psychiatry and emergency medicine).

2. Organizational factors

\section{1) Job demands}

The Chinese version ${ }^{20}$ of the Job Content Questionnaire $^{21)}$ was used to assess the job demands of respondents. The scale contained 5 items, with 5 response categories ranging from 1 (strongly disagree) to 5 (strongly agree). Items were modified slightly to apply to the health-care context. The items were "I perform excessive work to care for patients", "My job requires hard work", "I have insufficient time to perform my work tasks", "My job requires me to work very quickly", and "My job has conflicting demands". The Cronbach's alpha of this scale was 0.844 .

2) Safety climate

A 7-item scale with 5 response categories (from $1=$ strongly disagree to 5=strongly agree) was modified to apply to the study context according to the safety climate scale of Zohar and Luria ${ }^{18)}$. The current scale asked the respondents whether the management at their hospital does the following: "compliments workers who pay special attention to safety", "considers safety when setting our work speed and schedules", "discusses how to improve safety with us", "refuses to ignore safety rules when work falls behind schedule", "emphasizes safety procedures when we are working under pressure", "listens carefully to workers' ideas about improving safety", and "provides safety training for workers". The Cronbach's alpha of this scale was 
0.928 .

3) Organizational support

According to the findings of interviews with healthcare workers $^{22}$, 3 items and 5 response categories (from 1=strongly disagree to 5=strongly agree) were designed to measure the organizational support level. The items were "The other members of my medical team are friendly", "The other members of my medical team care about me", and "The other members of my medical team help me perform my medical duties". The Cronbach's alpha score of this scale was 0.936 .

4) Attendance at workplace violence training courses

The following 3 items were designed to assess respondents' experience of attendance at WPV-related training courses in the past 3 months: "protection from violent behavior", "management of interpersonal confliction", and "sexual harassment prevention". The respondents indicated whether they had attended each type of training using a binary scale $(0=$ did not attend, 1=attended). The results of the 3 items were summed as the score of WPV-related training (ranged from 0 to 3 ).

If respondents had attended any WPV-related training course in the past 3 months, the training course methods were also investigated by having the respondents indicate them by selecting from the following options (multiple-choice): "classroom lecture", "concrete practice", "Internet course", "monographic study", "institution visit", or "seminar".

\section{Data analysis}

Statistical analysis was performed using PASW Statistics Version 18.0 (SPSS, Chicago, IL, USA). The descriptive results of categorical variables such as physician personal characteristics and experience of WPV were expressed as the number and percentage of each category. Continuous variables such as age, tenure, and associated organizational factors of WPV against physicians were expressed as the mean \pm standard deviation (SD). For univariate analysis, the chi-squared test was adopted to assess the differences in categorical variables and whether physicians experienced threats or sexual harassment. The 2-sample $t$-test method was used to assess differences in the mean value for the continuous variables of different forms of WPV against physicians. A hierarchical logistic regression was conducted by regressing violent threats (yes vs. no) or sexual harassment (yes vs. no) on organizational factors (model 2) after controlling for age ${ }^{8)}$, gender ${ }^{4,8)}$, department ${ }^{5,8,9)}$, and tenure $^{7,10,11)}$ (model 1).

\section{Results}

Table 1 lists the descriptive results of respondent demographics, violent threats and sexual harassment, and associated factors. The mean age of the respondents was 43.31 years $(\mathrm{SD}=9.09)$, and $74.3 \%$ of them were male. The average tenure of the respondents was 7.88 years $(\mathrm{SD}=7.61)$, and $14.4 \%$ of the respondents were affiliated with departments (psychiatry and emergency medicine) with high exposure to WPV. Regarding the WPV in the past 3 months, $41.5 \%$ of respondents experienced at least one workplace-related violent threat (physical or verbal), and 9.8\% experienced at least one incident of sexual harassment. The mean ratings of job demands, safety climate, and organizational support were $18.61(\mathrm{SD}=3.21), 24.14$ $(\mathrm{SD}=4.54)$, and $11.53(\mathrm{SD}=1.96)$, all of which were near their median levels. The mean score of physician training rating was $0.33(\mathrm{SD}=0.63)$; in other words, participants attended fewer than one kind of the 3 listed WPV-related courses in the 3 months before the survey. Respondents who had attended WPV-related courses in the past 3 months reported that the most common form was lecture $(87.8 \%)$, followed by concrete practice $(30.6 \%)$, monographic study $(12.2 \%)$, Internet course $(8.2 \%)$, seminar $(8.2 \%)$, and institution visit $(6.1 \%)$.

The results of univariate analysis using the chi-squared test for categorical variables and the 2-sample $t$-test for continuous variables are presented in Table 2. Respondents in psychiatry and emergency medicine reported significantly higher incidences of both violent threats and sexual harassment. Respondents who experienced violent threats had less experience, poorer perceived safety climates, and higher job demands. Aside from department, no variable was significantly correlated with work-related sexual harassment. We further examine if violent threats had any clinical significance. Although there was no conventional cut-off point that reflected a clinical/dysfunctional level of violent threats or sexual harassment, a logical and a conservative approach to determining a dysfunctional level could be derived based on the average score for violent threats $(\bar{x}=0.329)$ among the departments that were exposed to low WPV. Average score for violent threats $(\bar{x}=0.24)$ in the high safety climate group (i.e., equal to or higher than the 75 th percentile for safety climate) was clearly below the dysfunctional level. In contrast, the average score for violent threats $(\bar{x}=0.63)$ in the low safety climate group (i.e., equal to or smaller than the 25th percentile for safety climate) was noticeably above the dysfunctional level. Similarly, the average score for violent threats $(\bar{x}=0.31)$ in the low job demand group (i.e., equal to or lower than the 25 th percentile for job demands) was below the dysfunctional level, whereas the average score for violent threats $(\bar{x}=0.64)$ in the high job demand group (i.e., equal to or higher than 
Table 1. Descriptive information of respondents including demographics, presence/absence of violent threats or sexual harassment in the workplace, and associated factors $(\mathrm{N}=189)$

\begin{tabular}{|c|c|c|c|}
\hline Variables & & $\mathrm{N}$ & $\%$ \\
\hline \multicolumn{4}{|l|}{ Categorical variables } \\
\hline \multicolumn{4}{|l|}{ Gender } \\
\hline Male & & 139 & 74.3 \\
\hline Female & & 48 & 25.7 \\
\hline Missing & & 2 & - \\
\hline \multicolumn{4}{|l|}{ Department ${ }^{\#}$} \\
\hline Low exposure to WPV & & 160 & 85.6 \\
\hline High exposure to WPV & & 27 & 14.4 \\
\hline Missing & & 2 & - \\
\hline \multicolumn{4}{|c|}{ Workplace violent threats in the past 3 months } \\
\hline No & & 107 & 58.5 \\
\hline Yes & & 76 & 41.5 \\
\hline Missing & & 6 & - \\
\hline \multicolumn{4}{|c|}{ Workplace sexual harassment in the past 3 months } \\
\hline No & & 165 & 90.2 \\
\hline Yes & & 18 & 9.8 \\
\hline \multirow[t]{2}{*}{ Missing } & & 6 & - \\
\hline & Range & Mean & SD \\
\hline \multicolumn{4}{|l|}{ Continuous variables } \\
\hline Age (years) & $25-65$ & 43.31 & 9.09 \\
\hline Tenure (years) in current department & $0-33$ & 7.88 & 7.61 \\
\hline Job demands & $10-25$ & 18.61 & 3.21 \\
\hline Safety climate & $10-35$ & 24.14 & 4.54 \\
\hline Organizational support & $3-15$ & 11.53 & 1.96 \\
\hline Attendance of training courses & $0-3$ & 0.33 & 0.63 \\
\hline
\end{tabular}

WPV=workplace violence. "Department with low exposure to WPV: departments other than psychiatry and emergency medicine. Department with high exposure to WPV: departments of psychiatry or emergency medicine.

the $75^{\text {th }}$ percentile for job demands) was above the dysfunctional level.

We used the above approach to examine if sexual harassment had any clinical significance, even though there was no significant association between sexual harassment and job demands or safety climate. The averages score for sexual harassment in both the high safety climate group $(\bar{x}=0.09)$ and low safety climate group $(\bar{x}=0.2)$ were above the dysfunctional level $(\bar{x}=0.08)$. Similarly, the averages score for sexual harassment in both the high job demand group $(\bar{x}=0.14)$ and the low job demand group $(\bar{x}=0.09)$ were above the dysfunctional level. Overall, these results failed to reach the clinical significance level.

To determine the factors related to physician exposure to WPV, a hierarchical logistic regression was conducted (Table 3). Department with exposure to WPV was found to be a significant determinant of both violent threats $(\mathrm{OR}=14.41 ; 95 \%$
$\mathrm{CI}=3.11-66.86)$ and sexual harassment $(\mathrm{OR}=4.74$, 95\% CI=1.30-17.26). Two organizational factors, namely safety climate $(\mathrm{OR}=0.89 ; 95 \% \mathrm{CI}=0.81-0.98)$ and job demands $(\mathrm{OR}=1.15 ; 95 \% \mathrm{CI}=1.02-1.30)$, were significant determinants of violent threats after controlling for personal characteristics factors.

\section{Discussion}

Although some studies of WPV in Taiwan healthcare settings have shown high prevalence rates among nurses, ranging from 33.6 to $63 \%$ across different units $^{23,24)}$, there is no available data in Taiwan about WPV prevalence rates among physicians. However, the increase in experiencing of WPV among physicians may be inferred from the Survey of Perceptions of Safety and Health in the Work Environment in Taiwan (Institute of Labor, Occupational Safety and Health, Taiwan Ministry of Labor [ILOSH]). The survey revealed that there was a significant in WPV 
Table 2. Univariate analysis of associated factors for violent threats and sexual harassment against physicians in the workplace in the past 3 months

\begin{tabular}{|c|c|c|c|c|c|c|c|c|c|c|}
\hline \multirow[b]{3}{*}{ Variables } & \multicolumn{5}{|c|}{ Violent threats } & \multicolumn{5}{|c|}{ Sexual harassment } \\
\hline & \multicolumn{2}{|c|}{ Yes } & \multicolumn{2}{|c|}{ No } & \multirow[b]{2}{*}{$p$} & \multicolumn{2}{|c|}{ Yes } & \multicolumn{2}{|c|}{ No } & \multirow[b]{2}{*}{$p$} \\
\hline & $\mathrm{n}$ & $\%$ & $\mathrm{n}$ & $\%$ & & $\mathrm{n}$ & $\%$ & $\mathrm{n}$ & $\%$ & \\
\hline \multicolumn{11}{|l|}{ Categorical variables } \\
\hline \multicolumn{11}{|l|}{ Gender } \\
\hline Male & 52 & 38.2 & 84 & 61.8 & 0.098 & 11 & 8.3 & 122 & 91.7 & 0.260 \\
\hline Female & 24 & 52.2 & 22 & 47.8 & & 7 & 14.6 & 41 & 85.4 & \\
\hline \multicolumn{11}{|l|}{ Department } \\
\hline Low exposure to WPV & 51 & 32.9 & 104 & 67.1 & $<0.001$ & 12 & 7.8 & 142 & 92.2 & 0.033 \\
\hline High exposure to WPV & 24 & 88.9 & 3 & 11.1 & & 6 & 22.2 & 21 & 77.8 & \\
\hline Continuous variables & Mean & $\mathrm{SD}$ & Mean & SD & $p$ & Mean & SD & Mean & SD & $p$ \\
\hline Age (years) & 42.39 & 8.56 & 43.53 & 9.36 & 0.405 & 41.61 & 7.82 & 43.18 & 9.10 & 0.483 \\
\hline Tenure (years) & 6.22 & 6.62 & 8.72 & 7.70 & 0.026 & 6.96 & 7.36 & 7.65 & 7.33 & 0.704 \\
\hline Safety climate & 22.85 & 4.46 & 24.98 & 4.46 & 0.002 & 22.28 & 4.21 & 24.25 & 4.57 & 0.082 \\
\hline Organizational support & 11.49 & 2.14 & 11.60 & 1.72 & 0.695 & 11.00 & 1.97 & 11.54 & 1.92 & 0.258 \\
\hline Job demands & 19.39 & 3.39 & 18.01 & 2.94 & 0.004 & 19.00 & 3.30 & 18.55 & 3.17 & 0.579 \\
\hline Attendance of training courses & 0.33 & 0.60 & 0.35 & 0.66 & 0.870 & 0.56 & 0.86 & 0.31 & 0.60 & 0.244 \\
\hline
\end{tabular}

WPV=workplace violence.

Table 3. Hierarchical logistic regression between related factors and physicians' exposure to violent threats and sexual harassment

\begin{tabular}{|c|c|c|c|c|c|c|c|c|}
\hline \multirow[b]{3}{*}{ Variables } & \multicolumn{4}{|c|}{ Violent threats (yes vs. no) } & \multicolumn{4}{|c|}{ Sexual harassment (yes vs. no) } \\
\hline & \multicolumn{2}{|c|}{ Model 1} & \multicolumn{2}{|c|}{ Model 2} & \multicolumn{2}{|c|}{ Model 1} & \multicolumn{2}{|c|}{ Model 2} \\
\hline & OR & $95 \% \mathrm{CI}$ & OR & $95 \% \mathrm{CI}$ & OR & $95 \% \mathrm{CI}$ & OR & $95 \% \mathrm{CI}$ \\
\hline Age (years) & 1.01 & $0.96-1.06$ & 1.02 & $0.96-1.07$ & 0.97 & $0.90-1.05$ & 0.96 & $0.88-1.04$ \\
\hline \multicolumn{9}{|l|}{ Gender } \\
\hline Male & \multicolumn{2}{|c|}{ (Reference) } & \multicolumn{2}{|c|}{ (Reference) } & \multicolumn{2}{|c|}{ (Reference) } & \multicolumn{2}{|c|}{ (Reference) } \\
\hline Female & 1.88 & $0.84-4.21$ & 2.29 & $0.96-5.47$ & 1.64 & $0.52-5.20$ & 1.61 & $0.47-5.44$ \\
\hline \multicolumn{9}{|l|}{ Department } \\
\hline Low exposure to WPV & \multicolumn{2}{|c|}{ (Reference) } & \multicolumn{2}{|c|}{ (Reference) } & \multicolumn{2}{|c|}{ (Reference) } & \multicolumn{2}{|c|}{ (Reference) } \\
\hline High exposure to WPV & $19.85^{*}$ & $4.38-90.02$ & $14.41 *$ & $3.11-66.86$ & $4.82 *$ & $1.47-15.79$ & $4.74 *$ & $1.30-17.26$ \\
\hline Tenure (years) & 0.97 & $0.91-1.03$ & 0.96 & $0.89-1.02$ & 1.02 & $0.92-1.13$ & 1.03 & $0.92-1.15$ \\
\hline Safety climate & & & $0.89 *$ & $0.81-0.98$ & & & 0.90 & $0.78-1.04$ \\
\hline Job demands & & & $1.15^{*}$ & $1.02-1.30$ & & & 1.00 & $0.84-1.20$ \\
\hline Organizational support & & & 1.05 & $0.85-1.30$ & & & 0.92 & $0.66-1.28$ \\
\hline Attendance of training courses & & & 0.99 & $0.56-1.76$ & & & 1.91 & $0.96-3.82$ \\
\hline -2log likelihood & \multicolumn{2}{|c|}{190.51} & \multicolumn{2}{|c|}{176.85} & \multicolumn{2}{|c|}{101.75} & \multicolumn{2}{|r|}{95.05} \\
\hline Nagelkerke $\mathrm{R}^{2}$ & \multicolumn{2}{|c|}{0.249} & \multicolumn{2}{|c|}{0.336} & \multicolumn{2}{|c|}{0.092} & \multicolumn{2}{|r|}{0.171} \\
\hline
\end{tabular}

WPV=workplace violence. ${ }^{*} p<0.05$. Model 1: This model included the following personal characteristics: respondents' gender, age, affiliated department, and tenure. Model 2: This model included the following personal characteristics and organizational factors: safety climate, job demands, organizational support, and attendance of training courses. 
incidents, $20.41 \%$ of which were violent threats and $3.94 \%$ of which were sex harassment, among healthcare and social welfare workers in 2013 ${ }^{25}$, compared with the levels among health-care and social welfare workers in 2010 (11.74\% for violent threats and $2.10 \%$ for sexual harassment $)^{26)}$.

This study revealed that WPV was a severe occupational hazard for physicians in Taiwan; more than $40 \%$ of the respondents experienced at least one workrelated verbal or physical threats in the 3 months before the study, and almost $10 \%$ experienced sexual harassment during the same period. Psychiatric and emergency medicine physicians reported significantly higher incidences of violent threats and sexual harassment. Because of the rapid increase in population in Taiwan between 1994 and 2000, and the implementation of Taiwan's National Health Insurance policy in 1995, the volume of health services delivered has greatly increased. These drastic changes have resulted in the current practice of the "three-minute patient visit" with physicians, that is, a short consultation with a doctor ${ }^{27}$. These "three-minute patient visits" may inevitably lead to complaints from patients or even aggressive acts toward physicians.

Among the predictors of violent threats against hospital physicians, safety climate was the most substantial. Safety climate, which measures the degree of practice and commitment to safety procedure of hospital management, is a critical organizational factor for worker health; improved compliance with safety practices in the workplace has been shown to increase worker safety and health ${ }^{28-30)}$. The safety climate concept was introduced into health-care workplaces in the late $1990 \mathrm{~s}$ and has proved to be positively related to health-care workers' safety practices in the occupational safety setting ${ }^{31-34)}$. Perceived safety climate was reported to be a protective factor for WPV that mediates the relationship between workderived violence and negative consequences, job satisfaction, and work engagement ${ }^{35}$. In Taiwan, although physicians are highly respected and autonomous when practicing medicine, improving their safety climate is critical to eliminating WPV.

Physicians' job demands were also determined to be a significant organizational predictor for violent threats. An excessive service volume ${ }^{5,6)}$, high-stress situations ${ }^{4,5)}$, and overload of physicians in daily practice $^{6)}$ could result in poor-quality medical care, in turn leading to dissatisfied patients, which is the leading cause of WPV against physicians. Hospital management could mitigate physician job demands through several organizational measures including increased staffing, job design, and administrative intervention. Hospital administrations should ensure sufficient health-care staffing levels to prevent WPV. In addi- tion, adequate job design is also essential to easing physicians' job demands. Such design changes may include a regular schedule with adequate rest periods, shorter shifts, less overtime, and duties that are commiserate with ability, that are autonomous, and that avoid overload ${ }^{1)}$.

Everyone has the right to work in a safe environment without the threat of violence. The World Medical Association (WMA) encourages undergraduate and postgraduate education providers to ensure that health-care professionals are trained in the communication skills necessary to resolve potentially violent situations ${ }^{2}$. In this study, although the results indicate that training course attendance was not a significant predictor in preventing WPV, of the respondents who had attended a training course in the previous 3 months, $87.8 \%$ had attended only lectures. These results imply that WPV training programs in hospital settings should provide more interactive and dynamic learning methods for clinical physicians. In addition, teaching strategies such as small-group learning, interactive learning, and simulation exercises may be applied during training in medical schools ${ }^{36}$.

No single factor other than affiliated department was significantly correlated with work-related sexual harassment, possibly because sexual harassment often results from the propensity toward sexual crime by the perpetrator. In addition to organizational intervention, hospital management is also responsible for providing organizational assistance to the victims of sexual harassment.

This study had several limitations. First, all participants were recruited from regional teaching hospitals in Northern Taiwan. Because the incidence of WPV varies strongly according to cultural differences, future studies must be cautious in applying these results to hospitals of different levels or in different regions. Second, this study yielded a low response rate; however, the relatively small 95\% CI supported the reliability for our findings. Third, the aim of this study was to explore the factors related to general violent threats, so the measurements combined verbal and physical violence to be in the same question. In the future, they could be separated into the two different types of violent threat items for further study. Finally, the cross-sectional design utilized in this study prevents us from making any causal conclusions, despite the significant direct effects reported in Table 3.

\section{Conclusion}

This study provids preliminary evidence indicating that WPV was a severe occupational hazard for physicians in Taiwan, particularly for those in psychiatry and emergency medicine, who reported significantly 
higher incidences of both violent threats and sexual harassment. Two organizational factors were positively associated with violent threats, namely safety climate and job demands. WPV policy should be a priority for hospital management and the government, both of which are responsible for providing sufficient support to avoid WPV and provide physical or psychosocial rehabilitation after WPV. In addition to their work performance, making appropriate job demands of physicians must also be a concern for hospital management.

Conflicts of interest: The authors declare that they have no competing interests.

This study was supported by a grant (\#NSC972511-S-030-001-MY3) from the National Science Council of the Executive Yuan, Taiwan. Its contents are solely the responsibility of the authors and do not necessarily represent the official views of the National Science Council.

Acknowledgments: This research was supported by a grant (\#NSC97-2511-S-030-001-MY3) from the National Science Council of the Executive Yuan, Taiwan.

\section{References}

1) ILO, ICN, WHO, PSI. Framework Guidelines for Addressing Workplace Violence in the Health Sector. [Online]. 2002 [cited 2014 May 21]: Available from: URL: http://www.who.int/violence_injury_prevention /violence/activities/workplace/en/

2) World Medical Association [WMA]. WMA statement on violence in the health sector by patients and those close to them. Adopted by the 63rd WMA general assembly, Bangkok, Thailand, October 2012. [Online]. 2012 [cited 2013 Apr 25]: Available from: URL: http://www.wma.net/en/30publications/ 10policies/v5/

3) Magin P, Adams J, Joy E, Ireland M, Heaney S, Darab S. Violence in general practice: perceptions of cause and implications for safety. Can Fam Physician 2008; 54: 1278-84.

4) Acik Y, Deveci SE, Gunes G, et al. Experience of workplace violence during medical specialty training in Turkey. Occup Med (Lond) 2008; 58: 361-6.

5) Behnam M, Tillotson RD, Davis SM, Hobbs GR. Violence in the emergency department: a national survey of emergency medicine residents and attending physicians. J Emerg Med 2011; 40: 565-79.

6) Carmi-Iluz T, Peleg R, Freud T, Shvartzman P. Verbal and physical violence towards hospital- and community-based physicians in the Negev: an observational study. BMC Health Serv Res 2005; 5: 54.

7) Kowalenko T, Walters BL, Khare RK, Compton $\mathrm{S}$; Michigan College of Emergency Physicians
Workplace Violence Task Force. Workplace violence: a survey of emergency physicians in the state of Michigan. Ann Emerg Med 2005; 46: 142-7.

8) Arimatsu M, Wada K, Yoshikawa T, et al. An epidemiological study of work-related violence experienced by physicians who graduated from a medical school in Japan. J Occup Health 2008; 50: 357-61.

9) Wu JC, Lin YW, Chen PY, Tang CS, Chen FL. The occupational exposure profiles for physicians in Taiwan. Chinese J Occup Med 2012; 19: 125-34 (in Chinese).

10) Morrison JL, Lantos JD, Levinson W. Aggression and violence directed toward physicians. J Gen Intern Med 1998; 13: 556-61.

11) Paola F, Malik T, Qureshi A. Violence against physicians. J Gen Intern Med 1994; 9: 503-6.

12) Findorff MJ, McGovern PM, Wall M, Gerberich SG, Alexander B. Risk factors for work related violence in a health care organization. Inj Prev 2004; 10: 296-302.

13) Anderson C. Training efforts to reduce reports of workplace violence in a community health care facility. J Prof Nurs 2006; 22: 289-95.

14) Trenoweth S. Perceiving risk in dangerous situations: risks of violence among mental health inpatients. J Adv Nurs 2003; 42: 278-87.

15) Hutchinson M, Wilkes L, Jackson D, Vickers MH. Integrating individual, work group and organizational factors: testing a multidimensional model of bullying in the nursing workplace. J Nurs Manag 2010; 18: 173-81.

16) Spector PE, Coulter ML, Stockwell HG, Matz MW. Perceived violence climate: a new construct and its relationship to workplace physical violence and verbal aggression, and their potential consequences. Work \& Stress 2007; 21: 117-30.

17) Yang LQ, Spector PE, Chang CH, Gallant-Roman M, Powell J. Psychosocial precursors and physical consequences of workplace violence towards nurses: a longitudinal examination with naturally occurring groups in hospital settings. Int J Nurs Stud 2012; 49: 1091-102.

18) Zohar D, Luria G. A multilevel model of safety climate: cross-level relationships between organization and group-level climates. J Appl Psychol 2005; 90: 616-28.

19) Chen PY, Li Y, Tuckey M, Cigularov KP. Chapter 9: Progress and Challenges in Occupational Health and Safety Research. In Leka S, Sinclair RR eds. Contemporary Occupational Health Psychology: Global Perspectives on Research and Practice, Volume 3. John Wiley \& Sons, Ltd. 2014.

20) Cheng Y, Luh WM, Guo YL. Reliability and validity of the Chinese version of the job content questionnaire in Taiwanese workers. Int J Behav Med 2003; 10: $15-30$.

21) Karasek R, Brisson C, Kawakami N, Houtman I, Bongers $\mathrm{P}$, Amick B. The job content questionnaire (JCQ): an instrument for internationally comparative assessments of psychosocial job characteristics. J 
Occup Health Psychol 1998; 3: 322-55.

22) Lin YW, Chuang TH, Liu HC, Chen YJ, Chen FL. Exploring job stressors for Head Nurses and Clinical Nurses from the Perspective of Their Job Characteristics. Taiwan Journal of Public Health 2011; 30: 245-56 (in Chinese).

23) Lin YH, Liu HE. The impact of workplace violence on nurses in South Taiwan. Int J Nurs Stud 2005; 42: 773-8.

24) Choy CS, Chiou HY, Chiu WT, Huang YW, Cheah $\mathrm{KP}$, Chen YC, Chou HT. A pilot study of violence on emergency department nurses in Taipei. J Taiwan Emerg Med 2006; 8: 126-33.

25) Institute of Labor, Occupational Safety and Health(ILOSH). Survey of Perceptions of Safety and Health in the Work Environment in 2013 Taiwan. Taipei: Institute of Labor, Occupational Safety and Health, Ministry of Labor, the Executive Yuan, Taiwan; 2013 (in Chinese).

26) Institute of Labor, Occupational Safety and Health(ILOSH). Survey of Perceptions of Safety and Health in the Work Environment in 2010 Taiwan. Taipei: Institute of Labor, Occupational Safety and Health, Ministry of Labor, the Executive Yuan, Taiwan; 2010 (in Chinese).

27) Cheng TM. Taiwan's new national health insurance program: genesis and experience so far. Health Aff 2003; 22: 61-76.

28) Gershon RRM, DeJoy DM, Borwegen B, et al. Chapter 6: Health and Safety Culture, In U.S. National Institute for Occupational Safety and Health [NIOSH]. A NORA report: State of the sector / health care and social assistance. DHHS (NIOSH) Publication No. 2009-139, 2009: 87-97.
[Online]. 2009 [cited 2012 Jun 7]: Available from: URL: http://www.cdc.gov/niosh/docs/2009-139/ pdfs/2009-139.pdf

29) Geiger-Brown J, Lipscomb J. The health care work environment and adverse health and safety consequences for nurses. Annu Rev Nurs Res 2010; 28 : 191-231.

30) Hudson P. Applying the lessons of high risk industries to health care. Qual Saf Health Care 2003; 12 (Suppl 1): i7-12.

31) Flin R, Burns C, Mearns K, Yule S, Robertson EM. Measuring safety climate in health care. Qual Saf Health Care 2006; 15: 109-15.

32) Eliseo LJ, Murray KA, White LF, Dyer S, Mitchell PA, Fernandez WG. EMS providers' perceptions of safety climate and adherence to safe work practices. Prehosp Emerg Care 2012; 16: 53-8.

33) Smith DR, Muto T, Sairenchi T, et al. Hospital safety climate, psychosocial risk factors and needlestick injuries in Japan. Ind Health 2010; 48: 85-95.

34) Gershon RRM, Pearson JM, Sherman MF, Samar SM, Canton AN, Stone PW. The prevalence and risk factors for percutaneous injuries in registered nurses in the home health care sector. Am J Infect Control 2009; 37: 525-33.

35) McCaughey D, DelliFraine JL, McGhan G, Bruning NS. The negative effects of workplace injury and illness on workplace safety climate perceptions and health care worker outcomes. Safety Science 2013; 51: $138-47$.

36) Tyler IV, Hau M, Buxton JA, et al. Canadian medical students' perceptions of public health education in the undergraduate medical curriculum. Acad Med 2009; 84: 1307-12. 